\title{
Evaluating Rainfall Errors in Global Climate Models through Cloud Regimes
}

\author{
Jackson Tan • Lazaros Oreopoulos • \\ 4 Christian Jakob • Daeho Jin
}

6 Received: date / Accepted: date
7 Abstract Global climate models suffer from a persistent shortcoming in their 8 simulation of rainfall by producing too much drizzle and too little intense rain. 9 This erroneous distribution of rainfall is a result of deficiencies in the representation of underlying processes of rainfall formation. In the real world, clouds are precursors to rainfall and the distribution of clouds is intimately linked to the rainfall over the area. This study examines the model representation of tropical rainfall using the cloud regime concept. In observations, these cloud regimes are derived from cluster analysis of joint-histograms of cloud properties retrieved from passive satellite measurements. With the implementation of satellite simulators, comparable cloud regimes can be defined in models. This enables us to contrast the rainfall distributions of cloud regimes in 11 CMIP5 models to observations and decompose the rainfall errors by cloud regimes. Many models underestimate the rainfall from the organized convective cloud regime, which in observation provides half of the total rain in the tropics. Furthermore, these rainfall errors are relatively independent of the model's accuracy in representing this cloud regime. Error decomposition reveals that the biases are compensated in some models by a more frequent occurrence of the cloud regime and most models exhibit substantial cancellation of rainfall errors from different regimes and regions. Therefore, underlying relatively accurate total rainfall in models are significant cancellation of rainfall errors from different cloud types and regions. The fact that a good repre-

J. Tan

NASA Goddard Space Flight Center, Greenbelt, MD, USA and Universities Space Research Association, Columbia, MD, USA

E-mail: jackson.tan@nasa.gov

L. Oreopoulos

NASA Goddard Space Flight Center, Greenbelt, MD, USA

C. Jakob

ARC Centre of Excellence for Climate System Science and School of Earth, Atmosphere and Environment, Monash University, Clayton, Victoria, Australia

D. Jin

NASA Goddard Space Flight Center, Greenbelt, MD, USA and Universities Space Research Association, Columbia, MD, USA 
sentation of clouds does not lead to appreciable improvement in rainfall suggests a certain disconnect in the cloud-precipitation processes of global climate models.

Keywords cloud regimes $\cdot$ model evaluation $\cdot$ model rainfall $\cdot$ tropics $\cdot$ CMIP5 . CFMIP2 - ISCCP

\section{Introduction}

Accurate projections of rainfall are vital to society in a changing climate for purposes ranging from monitoring flood hazards to managing water resources. However, this is hindered by longstanding errors in global climate models. These errors include the persistent underestimation of heavy rain (e.g., Dai 2006; Sun et al 2006; Stephens et al 2010), incorrect timing in the diurnal cycle (e.g., Yuan et al 2013), and poor simulations of intraseasonal variability (e.g., Lin et al 2006; Jiang et al 2015). Many of these errors have been variously attributed to deficiencies in the representation of subgrid-scale processes such as cloud microphysics (Kang et al 2015) and deep convection (Folkins et al 2014).

In the tropics, rainfall is intimately linked to clouds and convection. In particular, cloud regimes derived from passive satellite observations of cloud properties (Jakob and Tselioudis 2003; Rossow et al 2005) have been used as proxies for various convective states to study rainfall (Lee et al 2013; Tan et al 2013; Rossow et al 2013). Amongst the key results from these studies are: the existence of an organized convective cloud regime that is associated with exceptionally high rainfall and contributes to about half the total tropical rainfall despite a relatively low occurrence $(\sim 5-10 \%)$; the existence of other less organized convective regimes with a moderate amount of rainfall; and the generally nonprecipitating nature of the majority of cloud regimes. In particular, Rossow et al (2013) raises the question of how well global climate models are able to capture extreme rainfall when they lack a proper representation of organized convection.

Given the insights that cloud regimes can provide on precipitation, the goal of this study is to use similar cloud regimes to evaluate model rainfall and examine the rainfall-cloud relationship within 11 global climate models in the Coupled Model Intercomparison Project, Phase 5 (CMIP5) database, with the aim of contributing to an improvement in projections of tropical rainfall. Cloud regimes are routinely used in model evaluation due to the growing implementation of satellite simulators (Klein and Jakob 1999; Bodas-Salcedo et al 2011). Most of these studies focus on the representation of clouds, radiation, and climate sensitivity in the models (Williams et al 2005; Williams and Tselioudis 2007; Williams and Webb 2009; Tsushima et al 2013; Bodas-Salcedo et al 2014; Mason et al 2015; Jin et al 2017a,b), while some examined properties associated with particular weather systems or atmospheric phenomena (Gordon et al 2005; Chen and Del Genio 2009; Bodas-Salcedo et al 2012). A few studies even used cloud regimes to better understand the effects of climate change (Williams and Tselioudis 2007; Tsushima et al 2016). However, to our knowledge, there have been no studies that evaluated the performance of model rainfall through the lens of cloud regimes. As such, this study will be the first to dissect errors in model rainfall through simulated cloud properties. We will show a general underestimation of rainfall associated with the cloud regime that is associated with organized convection in observations, and 


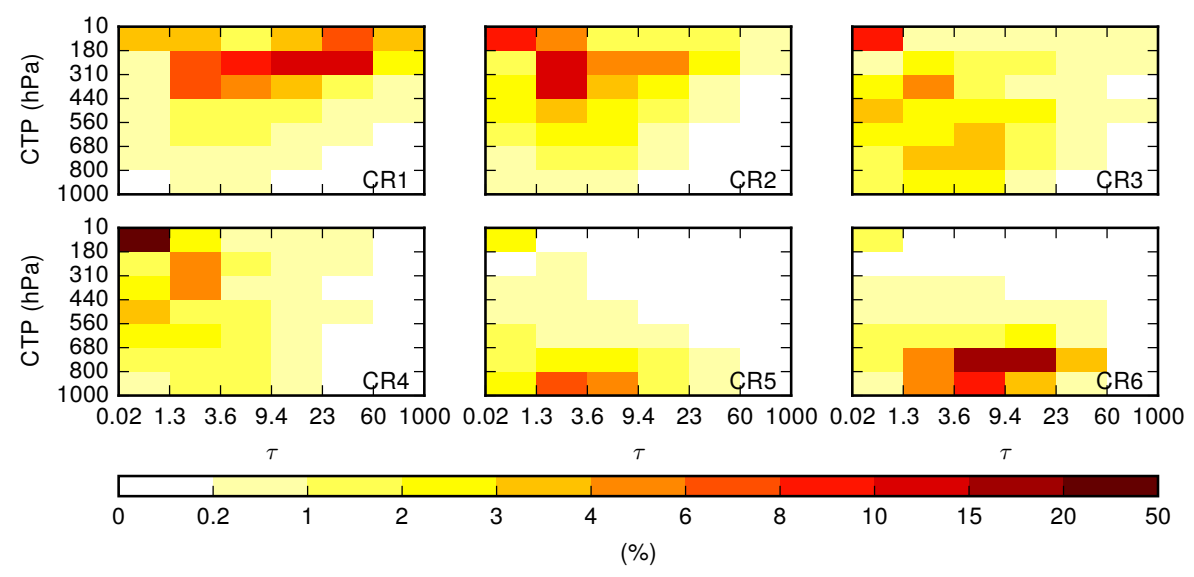

Fig. 1 Mean joint-histograms (or centroids) of the six ISCCP cloud regimes.

this underestimation can be traced to incorrect rain rates associated with cloud properties. We will also show that rainfall errors when specific regimes occur are compensated by the errors in their frequencies and geographical distributions.

\section{Data}

\subsection{Observations}

The International Satellite Cloud Climatology Project (ISCCP) D1 dataset provides joint-histograms of cloud occurrences as a function of cloud top pressure (CTP) and optical thickness $(\tau)$, constructed from passive retrievals on board a network of geostationary and polar-orbiting satellites (Rossow and Schiffer 1999). These 7 CTP-bin $\times 6 \tau$-bin joint-histograms describe the distribution of cloud properties within $280 \mathrm{~km} \times 280 \mathrm{~km}$ grids at three-hour intervals during sunlit hours from July 1983 to December 2009. Applying a $k$-means clustering algorithm to these joint-histograms objectively categorizes them into different cloud regimes or weather states (Jakob and Tselioudis 2003; Rossow et al 2005). We repeated their approach over the tropics $\left( \pm 15^{\circ} \mathrm{N} / \mathrm{S}\right)$ but with daytime-averaged joint-histograms (so that the daily time resolution matches that of the model outputs) and obtained six cloud regimes (Fig. 1), similar to those of Rossow et al (2005). Each daytime-averaged joint-histogram is then assigned to the cloud regime with the closest matching pattern; specifically, the daytime-averaged joint-histogram is assigned to the cloud regime that has the lowest Euclidean distance between the 42 -dimensional vector from the $7 \times 6$ bins of the joint-histogram and the same vector corresponding to the cloud regime centroid (Fig. 1). The daily cloud regime field is then regridded from the native $280 \mathrm{~km}$ equal-area grid to a $2.5^{\circ}$ equal-angle grid using the nearest neighbor technique. The geographical distributions of the six cloud regimes are shown in Fig. 2.

One of the six cloud regimes, CR1, has a mean joint-histogram that describes a prevalence of deep convective clouds with widespread stratiform anvil clouds 


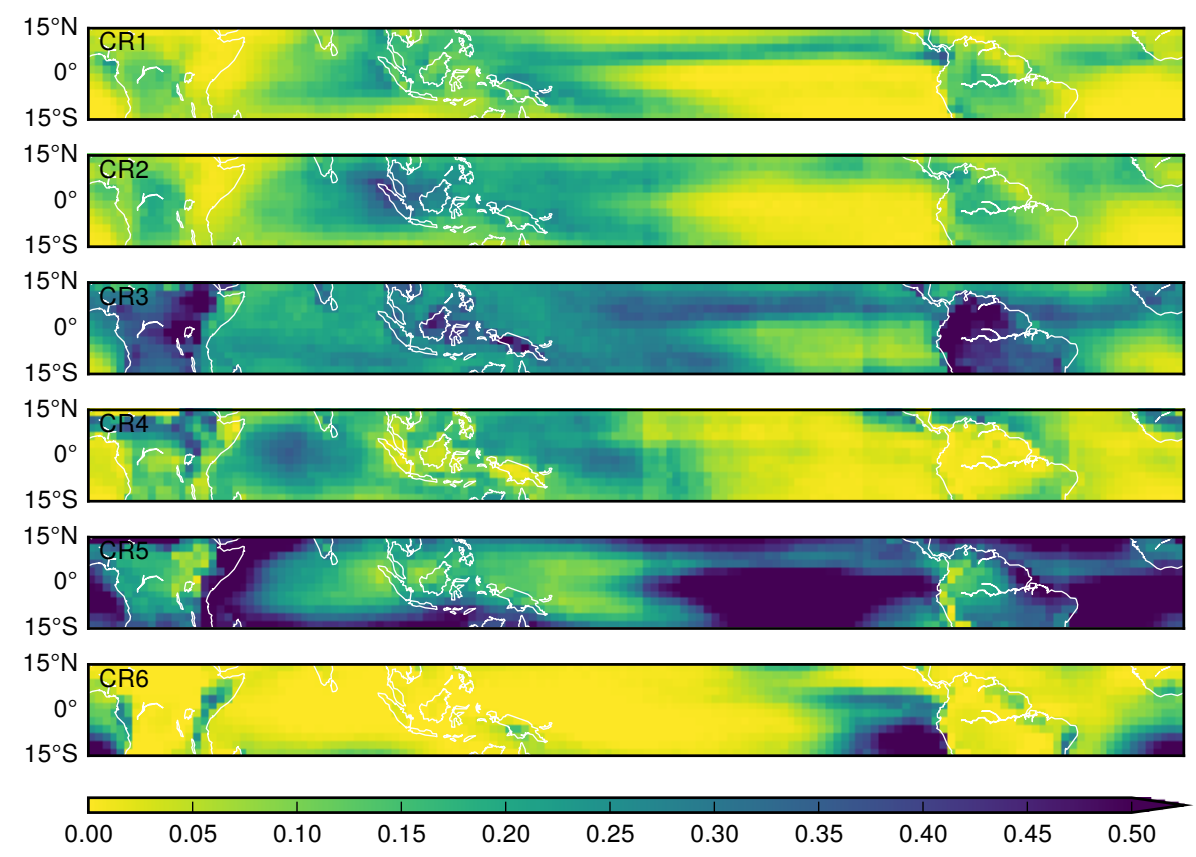

Fig. 2 Geographical distribution of the six ISCCP cloud regimes.

(Fig. 1). The cloud regime generally resides in regions of frequent, vigorous convection such as in the Intertropical Convergence Zone and the Tropical Western Pacific (Fig. 2). Based on its cloud distribution, geographical location, heating profile, cloud radiative effect and large-scale environment, CR1 has been identified as intense organized convection in previous studies (Jakob and Schumacher 2008; Oreopoulos and Rossow 2011; Rossow et al 2013; Stachnik et al 2013; Tan et al 2013, 2015). The two other convectively-active cloud regimes, CR2 and CR3, describe more isolated modes of convection. Other studies have found that they have weaker ascending motions and heating profiles (Stachnik et al 2013; Handlos and Back 2014). From its mean joint-histogram, CR2 has a lower population of deep convective clouds and a greater population of cirrus clouds, though its geographical distribution is broadly similar to CR1. CR2 has been observed to co-vary with CR1, suggesting a potential role in the life cycle of large convective systems that is often represented by CR1 (e.g., Tromeur and Rossow 2010; Mekonnen and Rossow 2011; Tan et al 2013). CR3, on the other hand, is characterized by a variety of lower and thinner clouds, some of which are consistent with cumulus congestus clouds. With a greater frequency of occurrence than CR1 or CR2 (Table 1), CR3 occurs in more regions of the tropics especially over land, though over areas of orography these "mid-level" clouds ${ }^{1}$ may be close to the surface and thus morphologically different from those over the ocean. CR4, CR5 and CR6 inhabit convectively-suppressed environments and represent a thin cirrus regime, trade cumulus or fair weather regime, and stratocumulus regime respectively. As we will

\footnotetext{
1 Strictly speaking, these are clouds whose tops are located in the mid-level altitudes.
} 
Table 1 Frequencies of the six cloud regimes in observations (ISCCP) and in the models, based on the 42-dimensional vector approach.

\begin{tabular}{|l|c|c|c|c|c|c|}
\hline Dataset & CR1 & CR2 & CR3 & CR4 & CR5 & CR6 \\
\hline \hline ISCCP & 0.085 & 0.116 & 0.225 & 0.114 & 0.391 & 0.068 \\
\hline all & 0.104 & 0.020 & 0.190 & 0.245 & 0.372 & 0.069 \\
\hline bcc-csm1-1-m & 0.083 & 0.011 & 0.230 & 0.320 & 0.328 & 0.028 \\
\hline CanAM4 & 0.142 & 0.026 & 0.107 & 0.211 & 0.453 & 0.061 \\
\hline CCSM4 & 0.114 & 0.003 & 0.241 & 0.215 & 0.398 & 0.029 \\
\hline CNRM-CM5 & 0.090 & 0.024 & 0.139 & 0.321 & 0.387 & 0.039 \\
\hline GFDL-CM3 & 0.121 & 0.019 & 0.103 & 0.471 & 0.204 & 0.083 \\
\hline GISS-E2-R & 0.093 & 0.021 & 0.181 & 0.227 & 0.377 & 0.103 \\
\hline HadGEM2-A & 0.106 & 0.041 & 0.183 & 0.188 & 0.384 & 0.098 \\
\hline IPSL-CM5B-LR & 0.074 & 0.027 & 0.160 & 0.388 & 0.329 & 0.022 \\
\hline MIROC5 & 0.091 & 0.000 & 0.183 & 0.017 & 0.483 & 0.226 \\
\hline MPI-ESM-LR & 0.075 & 0.028 & 0.096 & 0.429 & 0.290 & 0.082 \\
\hline MRI-CGCM3 & 0.142 & 0.040 & 0.215 & 0.185 & 0.368 & 0.049 \\
\hline
\end{tabular}

see in Sec. 3.1, these three cloud regimes are generally nonprecipitating and thus excluded from most of the subsequent analyses.

For an observationally-based dataset of rainfall, we use the rainfall estimates from Tropical Rainfall Measuring Mission (TRMM) Multisatellite Precipitation Analysis (TMPA; also known as TRMM 3B42) Research product, Version 7 (Huffman et al 2007). TMPA uses the TRMM Precipitation Radar and TRMM Microwave Imager to calibrate and combine high quality estimates from passive microwave instruments on board low-Earth-orbit satellites. Gaps in data are filled in by lower quality estimates from geosynchronous infrared measurements that are calibrated against microwave estimates on a monthly basis. Values over land are adjusted with gauges using the monthly gridded product from Global Precipitation Climatology Centre to control for biases arising from long-term drifts. TMPA has a resolution of $0.25^{\circ}$ at 3 -hour intervals, covering up to $\pm 50^{\circ}$ latitudes with data beginning in 1998 . The rain rate field is averaged to $2.5^{\circ}$ and daily resolution. Note that the accumulation period is over the full day instead of just over sunlit hours. This choice is to be consistent with the model data (Sec. 2.2), even though it will result in a discrepancy between the observation time periods of the cloud and precipitation data. Nevertheless, using daytime-averaged rain rates does not produce substantially different results than using daily-averaged rain rates (see Fig. 5 and Fig. S1).

\subsection{Models}

We utilize the models available in the Coupled Model Intercomparison Project, Phase 5 (CMIP5) (Taylor et al 2012). As part of the Cloud Feedback Model Intercomparison Project, Phase 2 (Bony et al 2011), many of these models produce ISCCP-like joint-histograms (variable clisccp) using the ISCCP satellite simulator (Klein and Jakob 1999; Bodas-Salcedo et al 2011). These joint-histograms differ from those in ISCCP by having 7 bins in $\tau$ as opposed to 6 , which we resolve by summing the first two $\tau$-bins. This yields a lowest $\tau$-bin of $0-0.3$, which is arguable close to the $0.02-1.27$ in ISCCP than the $0.3-1.3$ if we were to discard the first $\tau$-bin (see Jin et al 2017a for a detailed discussion). We also use precipi- 
Table 2 CMIP5 models used in this study. All models are run under the AMIP experiment setup. We select only one ensemble member from each model.

\begin{tabular}{|c|c|c|c|}
\hline No. & Model Name & lat $\left(^{\circ}\right) \times \operatorname{lon}\left({ }^{\circ}\right)$ & Modeling Center \\
\hline 1 & bcc-csm1-1-m & $1.121 \times 1.125$ & $\begin{array}{l}\text { Beijing Climate Center, China Meteoro- } \\
\text { logical Administration }\end{array}$ \\
\hline 2 & CanAM4 & $2.791 \times 2.812$ & $\begin{array}{l}\text { Canadian Centre for Climate Modelling } \\
\text { and Analysis }\end{array}$ \\
\hline 3 & CCSM4 & $0.942 \times 1.250$ & $\begin{array}{l}\text { National Center for Atmospheric Re- } \\
\text { search }\end{array}$ \\
\hline 4 & CNRM-CM5 & $1.401 \times 1.406$ & $\begin{array}{l}\text { Centre National de Recherches } \\
\text { Météorologiques / Centre Européen } \\
\text { de Recherche et Formation Avancée en } \\
\text { Calcul Scientifique }\end{array}$ \\
\hline 5 & GFDL-CM3 & $2.000 \times 2.500$ & $\begin{array}{l}\text { NOAA Geophysical Fluid Dynamics } \\
\text { Laboratory }\end{array}$ \\
\hline 6 & GISS-E2-R & $2.000 \times 2.500$ & $\begin{array}{l}\text { NASA Goddard Institute for Space Stud- } \\
\text { ies }\end{array}$ \\
\hline 7 & HadGEM2-A & $1.250 \times 1.875$ & Met Office Hadley Centre \\
\hline 8 & IPSL-CM5B-LR & $1.895 \times 3.750$ & Institut Pierre-Simon Laplace \\
\hline 9 & MIROC5 & $1.401 \times 1.406$ & $\begin{array}{l}\text { Atmosphere and Ocean Research Insti- } \\
\text { tute (The University of Tokyo), National } \\
\text { Institute for Environmental Studies, and } \\
\text { Japan Agency for Marine-Earth Science } \\
\text { and Technology }\end{array}$ \\
\hline 10 & MPI-ESM-LR & $1.865 \times 1.875$ & $\begin{array}{l}\text { Max-Planck-Institut für Meteorologie } \\
\text { (Max Planck Institute for Meteorology) }\end{array}$ \\
\hline 11 & MRI-CGCM3 & $1.121 \times 1.125$ & Meteorological Research Institute \\
\hline
\end{tabular}

tation flux (variable pr) in the models. Both variables have a daily resolution, but precipitation is the average over the full day and the joint-histograms are averages over the sunlit hours. We restrict ourselves to the AMIP experiment, which uses prescribed sea surface temperatures. After leaving out IPSL-CM5A-LR and IPSL-CM5A-MR due to issues with the implementation of the ISCCP simulator (J.-L. Dufresne, personal communication, 9th June 2015; see also http://cmippcmdi.llnl.gov/cmip5/errata/cmip5errata.html), we use a total of 11 models in this study (Table 2). We select the ensemble member $\mathrm{r} 1 \mathrm{i} 1 \mathrm{p} 1$ for all models except for GISS-E2-R and CCSM4, which only have the variable clisccp for ensemble member r6i1p1 and $\mathrm{r} 7 \mathrm{i} 1 \mathrm{p} 1$ respectively.

The existence of the ISCCP-like joint-histograms allows us to define cloud regimes in the models. Since our goal is to evaluate models against observations, we choose to assign model joint-histograms to observed cloud regimes based on the Euclidean distance of the vector formed by each model joint-histogram to the vector formed by the observed cloud regime centroid. There are two ways to construct this vector: (i) we can simply use each of the $7 \times 6$ bins in the joint-histogram to form a 42-dimensional vector; or (ii) we can use a reduced 3dimension vector formed by total cloud cover, mean cloud top pressure and mean albedo, which provides greater tolerance to minor errors in histogram binning (e.g. Gordon et al 2005; Williams and Webb 2009; Jin et al 2017b). We adopted the first approach of the 42-dimensional vectors for the following reason. As we will see, CR1 has a rain rate that is significantly higher than other CRs. Consequently, it is more important that we are able to capture the statistics of CR1 accurately. Table 1 shows that CR1 frequencies across the models are more reasonable in the 
42-dimensional vector approach as compared to the 3-dimensional vector approach (Table S1), which vastly overestimates the occurrence of CR1 for many models. Furthermore, the supposed disadvantage of the 42 -dimensional vector approachin which a slightly incorrect pixel placed into a neighboring CTP- $\tau$ bin is penalized as harshly as any other incorrect bin - is actually not so severe because of the tendency for cloud distributions to "clump" in the CTP- $\tau$ space. Hence, we chose to identify model CRs by matching the 42 -dimensional vector from the jointhistogram to the observed CR centroids. The mean joint-histograms of the model CR1, CR2 and CR3 are shown in Fig. 3, and the anomalies in their geographical distributions are shown in Fig. 4. In these figures, "all" refers to the aggregate data from all models. The other CRs are ignored because of their negligible effect on tropical rainfall (as will be discussed in Sec. 3.1).

In general, CR1 in the models have a predominance of thick and high clouds, just as with observations. However, their mean joint-histograms display a greater occurrence of thin cirrus clouds, as well as a tendency in some models (e.g. CCSM4 and GFDL-CM3) to produce clouds that are too high. The models are on aggregate able to reproduce the frequencies of CR1, which may be unexpected given that CR1 largely represents organized convection in observations, while models are known to be lacking in a representation of organized convection in their parametrization schemes (e.g., Arakawa 2004). For CR2, models produce clouds that are slightly too high and thin but still retaining a strong resemblance to observations. However, all models severely underestimate the frequency of CR2 (Table 1). On the other hand, the mean joint-histograms of model CR3 are more varied, with a high population of thin cirrus clouds and, at the same time, mid-level clouds that are considerable thicker. On one hand, it is not surprising that clouds in model CR3 are more varied than $\mathrm{CR} 1$ and $\mathrm{CR} 2$; looking at the centroids that model joint-histograms were assigned to Fig. 1, CR3 has the highest population of clouds in the center of the joint-histogram, so naturally most mid-level clouds in the models would tend to fall into CR3. On the other hand, the mean joint-histograms of model CR3 have a higher occurrence of thicker mid-level clouds, which may be reflecting a potential bias in many models. In any case, this shows that model cloud regimes may deviate in their patterns from observed cloud regimes, and this will be a subject of investigation in Sec. 3.1.

Just as with observations, we restrict our analysis to the tropics $\left( \pm 15^{\circ}\right.$ latitude). We perform our analysis over the period of 2001-2008, which provides us with a sufficient sample size for our analysis. In examining the geographical distributions, the variables need to be on the same grid, so for these analyses we interpolate them onto the $2.5^{\circ}$ ISCCP grids using the nearest neighbor technique. For all other tropics-averaged analyses, we retain the variables in their native grids, and select ocean-only points to avoid ISCCP retrieval biases (see Tan et al 2013).

\section{Results}

\subsection{Rain rate distributions}

All six observed cloud regimes have different distributions of rain rates (Fig. 5). CR1 has the highest rain rates, which generally decline as we progress towards CR6. In particular, CR1 has a unique rain rate distribution, with strikingly high 


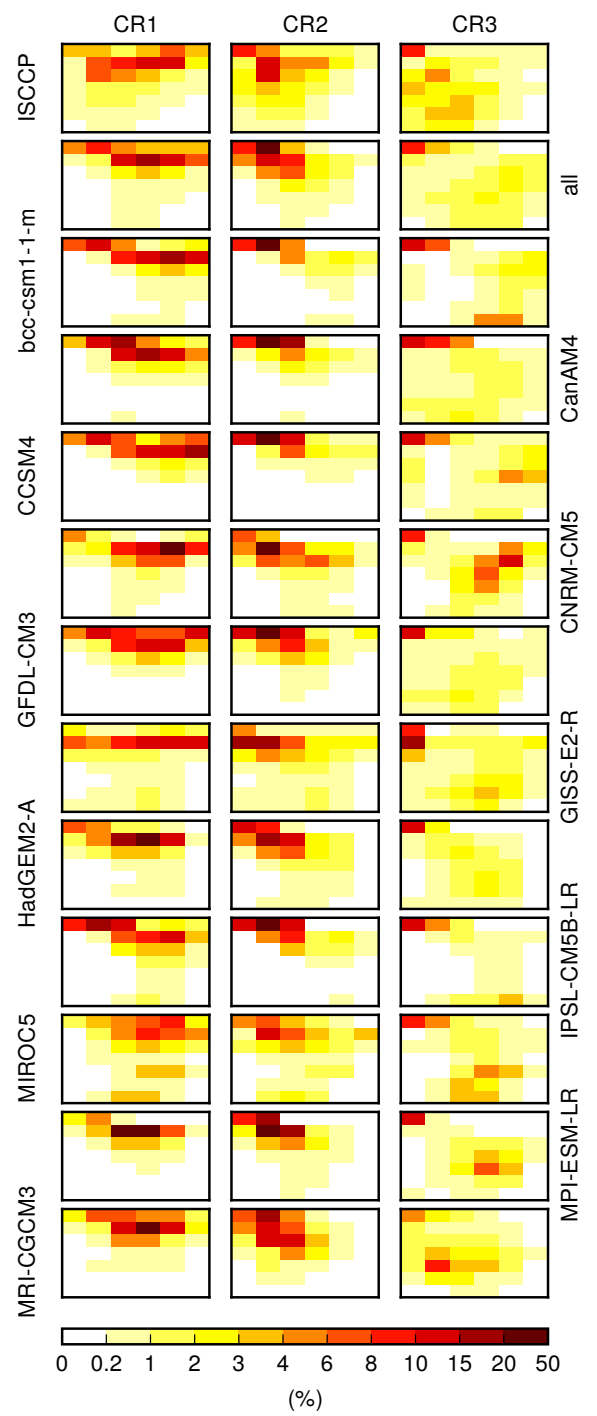

Fig. 3 Mean joint-histograms of model CR1, CR2 and CR3, derived through the 42dimensional vector approach. "all" refers to the mean of joint-histograms from all models. The ISCCP mean joint-histograms are included for ease of comparison.

rain occurrence (i.e. nonzero rain rates) and rain rate values. This is consistent with previous studies (Lee et al 2013; Tan et al 2013, 2015), which found that CR1 contributes to about half the total rainfall in the tropics. This intense rainfall reflects the fact that CR1 represents organized convection, which is associated with intense deep convection and large areas of stratiform rain. The next two regimes with the highest rainfall are CR2 and CR3. While their rain rates are not as high as CR1, they still have significant occurrences of rain. Both have similar distributions, which is perhaps due to the fact that both represent less organized 


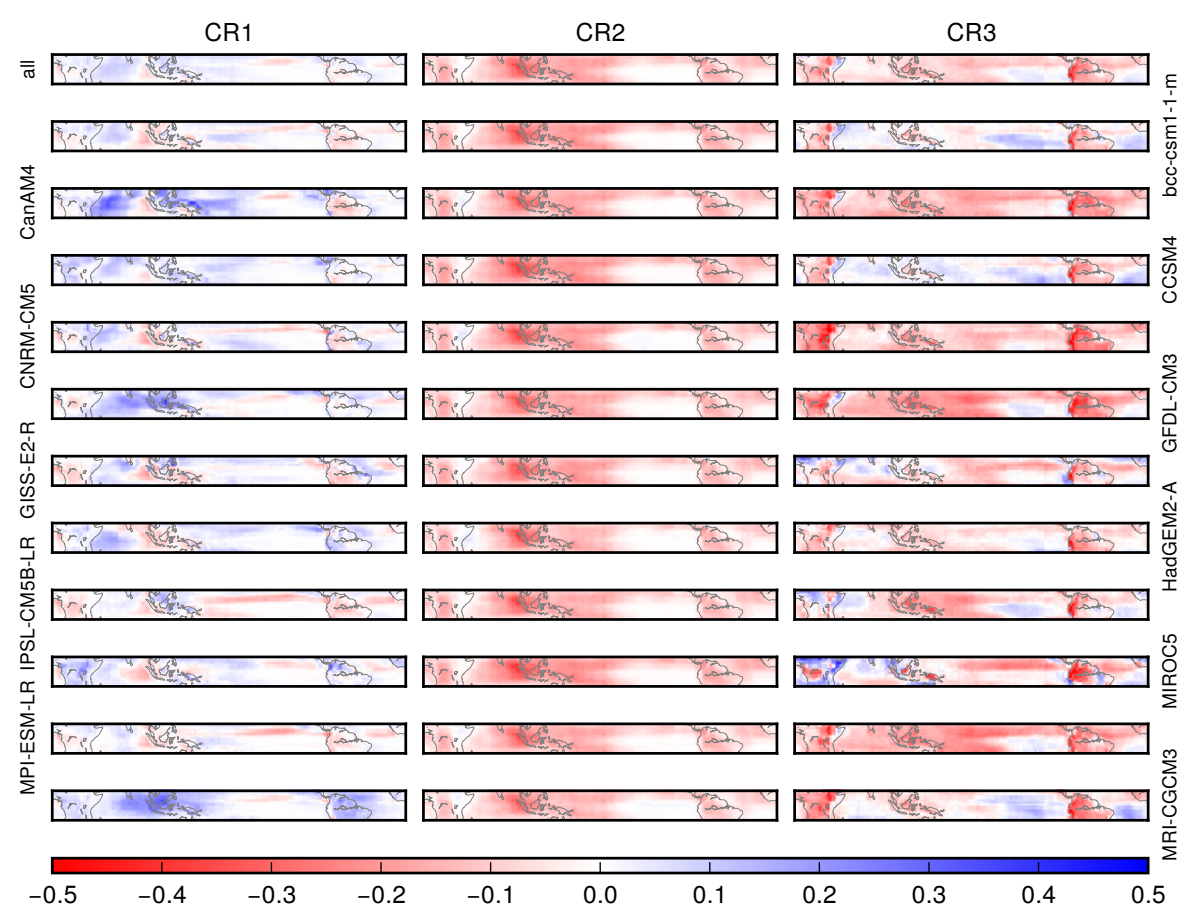

Fig. 4 Anomalies in the geographical distribution of the frequencies of CR1, CR2 and CR3 of the models; i.e. the geographical distribution of model regimes minus the geographical distribution of observed regimes (Fig. 2). Note that we chose blue to indicate positive anomaly due to its association with wet conditions.

forms of convection. CR4, CR5, and CR6 are associated with low rain rates and have no rain most of the time. These nonprecipitating regimes reside in subsiding environments (Tan et al 2013; Handlos and Back 2014) and contribute little to the total tropical rainfall despite a comparatively high frequency of occurrence. Due to the high impact of CR 1 to CR3 on rainfall - which together contribute $85 \%$ of the total tropical rainfall (Fig. 5) — we will focus on these three convectively-active cloud regimes from here on.

With the observed regime rain rate distribution in mind, we now investigate the rain rates from the models. Fig. 6 shows the distributions and statistics from observations (left-half of the "violin") and various models (right-half of the "violin"). Note that the left-half of the "violin" (observations) are identical across the models and are repeated to facilitate the comparison. The "all" category is based on the combined set of values from all models. For CR1 (Fig. 6a), many models struggle to reproduce the high rain rates of the observations. Some models, such as bcc-csm1-1-m, GISS-E2-R and MRI-CGCM3, have too many incidences of no-rain. The distributions of some other models, such as CNRM-CM5, have the correct shape but are biased low. However, a few models, such as CCSM4, HadGEM2-A and MIROC5, are broadly able to capture both the distribution and the statistics of the rain rates in CR1. Interestingly, the high upper-whisker (95th percentile) for IPSL-CM5B-LR indicates the presence of more outliers than in ob- 


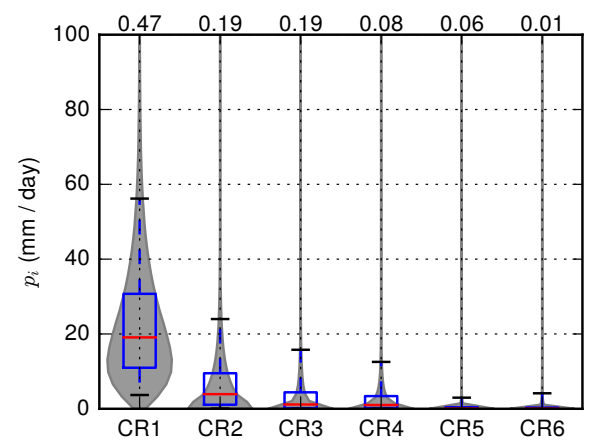

Fig. 5 "Violin" diagrams (Hintze and Nelson 1998) showing the distributions (gray curves), the median (red line), the interquartile range (blue box) and the 5th and 95th percentiles (whiskers) of rain rates for each ISCCP cloud regime. Numbers at top show the fractional contribution to total tropical rainfall.

servations, implying the existence of a long tail in the distribution. This can also been seen in bcc-csm1-1-m, though in this case the overall low values suppresses the magnitude of the outliers.

For CR2 and CR3 (Figs. 6b and c), the rain rate distributions of the models show varying degrees of fidelity. Just as with CR1, some models, such as bcc-csm11-m, underestimate the rain rates. However, unlike for CR1, there are models, such as IPSL-CM5B-LR and MPI-ESM-LR, that are significantly biased high. As for incidences of no-rain, some models overestimate its occurrence (e.g. MRICGCM3 for CR2 and CR3) while some underestimate it (e.g. MIROC5 for CR2). However, because of the overestimation and underestimation of various models, the combined values for CR2 and CR3 from all models have distributions and statistics that resemble observations.

While it appears that the rain rates of the three cloud regimes in these 11 climate models are deficient in a myriad of ways, there is the possibility that these errors arose because of a poor identification of model cloud regimes. Recall that model regimes are derived by assigning model joint-histograms to the closest centroids of observed regimes - where closest is defined by the lowest Euclidean distance between the $7 \times 6$ dimensional vectors formed by the bins of the joint-histograms and the observed regime centroid - and this assignment and thus the model cloud regimes may not perfectly capture the dominant cloud patterns within the models. We investigate whether the rain rate errors in Fig. 6 can be attributed to a poor identification of model cloud regimes by selecting the $10 \%$ of joint-histograms that have the lowest Euclidean distances in the assignment process. That is, these model cloud regimes are the subsets that most resemble their observational counterpart (Fig. 1). The mean joint-histograms of these subsets are shown in Fig. 7. Overlaying the rain rate distributions of these subsets over the original model distributions, we can see a mixed response from these "better" cloud regimes (Fig. 8). In some cases, such as CR1 in IPSL-CM5B-LR and CR2 in GFDL-CM3, the subsets possess rain rate distributions that are closer to observed values. In some cases, such as CR1 in CNRM-CM5 and CR3 in MIROC5, the subset has worse distributions. However, in many cases, there is no discernible difference between the subset and the entire population of model regimes. This 

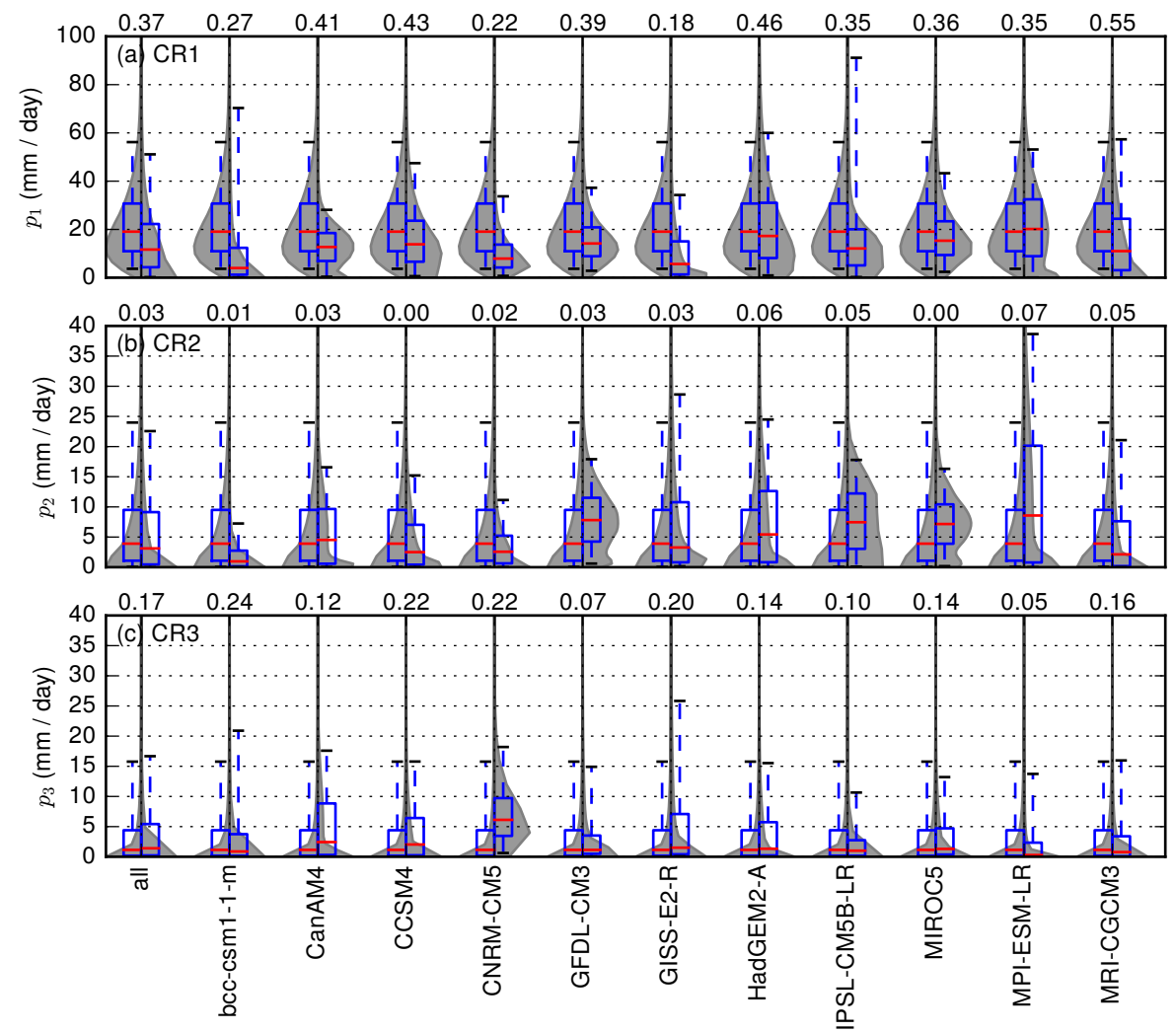

Fig. 6 "Violin" diagrams showing the distributions and statistics of rain rates for CR1, CR2 and CR3 of each model. The left-half of each "violin" corresponds to observations (Fig. 5) while the right-half shows the distribution from the model CR. Note the difference in scale between the subplots. See Fig. 5 on interpreting the diagram.

implies that the accuracy of the rain rate distributions of these three regimes in the models is unrelated to how well the models represent clouds.

\subsection{Error decomposition}

For the overall rainfall in the tropics, the rain rates of the cloud regimes in the previous section are only part of the picture; they describe only how much rain falls when a regime occurs in a grid box. How frequent the regimes occur also affect the total rainfall. To obtain a better idea of the contributions from various aspects of the regimes, we assume that total rainfall can be expressed as the frequencyweighted average of regime rain rates, $P_{o}=\sum_{i} f_{i, o} \times p_{i, o}$, where $f_{i, o}$ and $p_{i, o}$ are the frequency and rain rate of $\mathrm{CR} i$ for the observations (indicated by the subscript ' $\mathrm{o}$ ') and likewise for the models. We can then decompose the total rainfall error $\Delta P$ into,

$$
\Delta P=\sum_{i}\left(\Delta f_{i} \times p_{i, o}+f_{i, o} \times \Delta p_{i}+\Delta f_{i} \times \Delta p_{i}\right),
$$




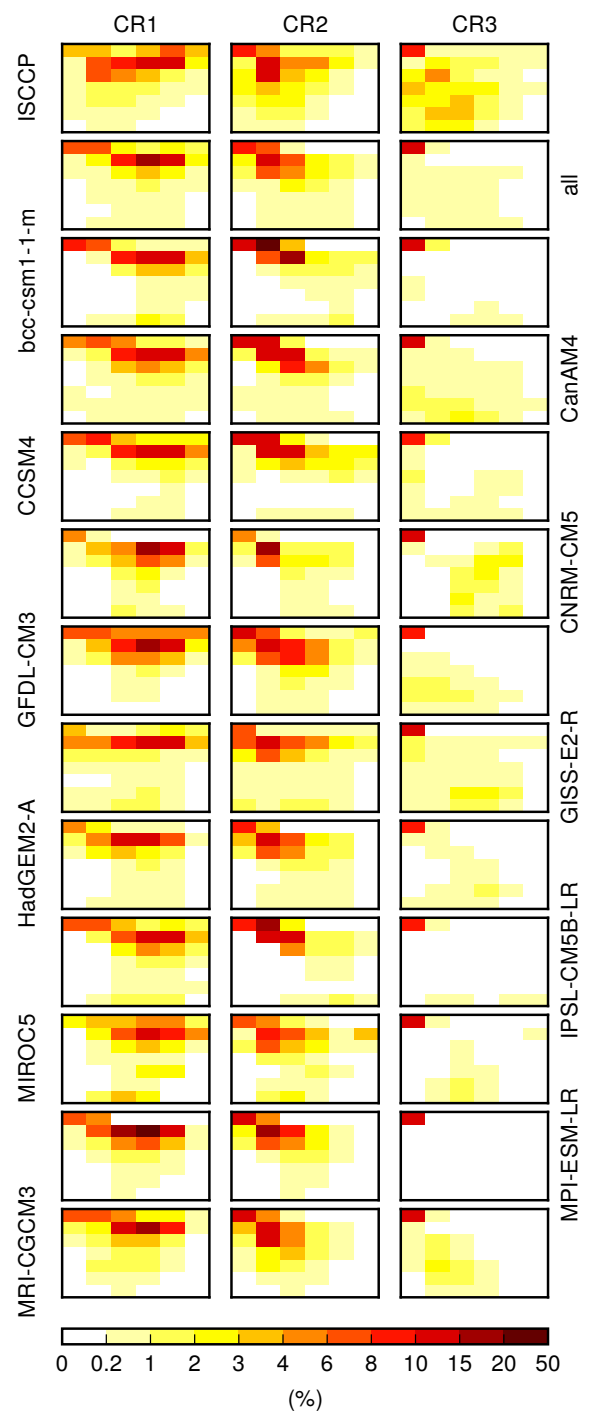

Fig. 7 Mean joint-histograms from the subset of "best-matching" model CR1, CR2 and CR3, based on the $10 \%$ of joint-histograms with lowest Euclidean distance in the assignment process. The ISCCP mean joint-histograms are included for ease of comparison.

where $\Delta$ denotes model minus observations. The three components in Eq. (1) represents the contribution due to error in the frequency of the regime $(\Delta f \times p)$, the contribution due to error in the rain rate of the regime $(f \times \Delta p)$, and the contribution due to the second-order co-variational error in the frequency and rain rate of the regime $(\Delta f \times \Delta p)$. These terms, together with the sum of all three terms for each model and regime, are shown in Fig. 9.

We begin first with the contribution from errors in the rain rates $(f \times \Delta p)$. The salient points from the previous section are reflected in Fig. 9: the universal 

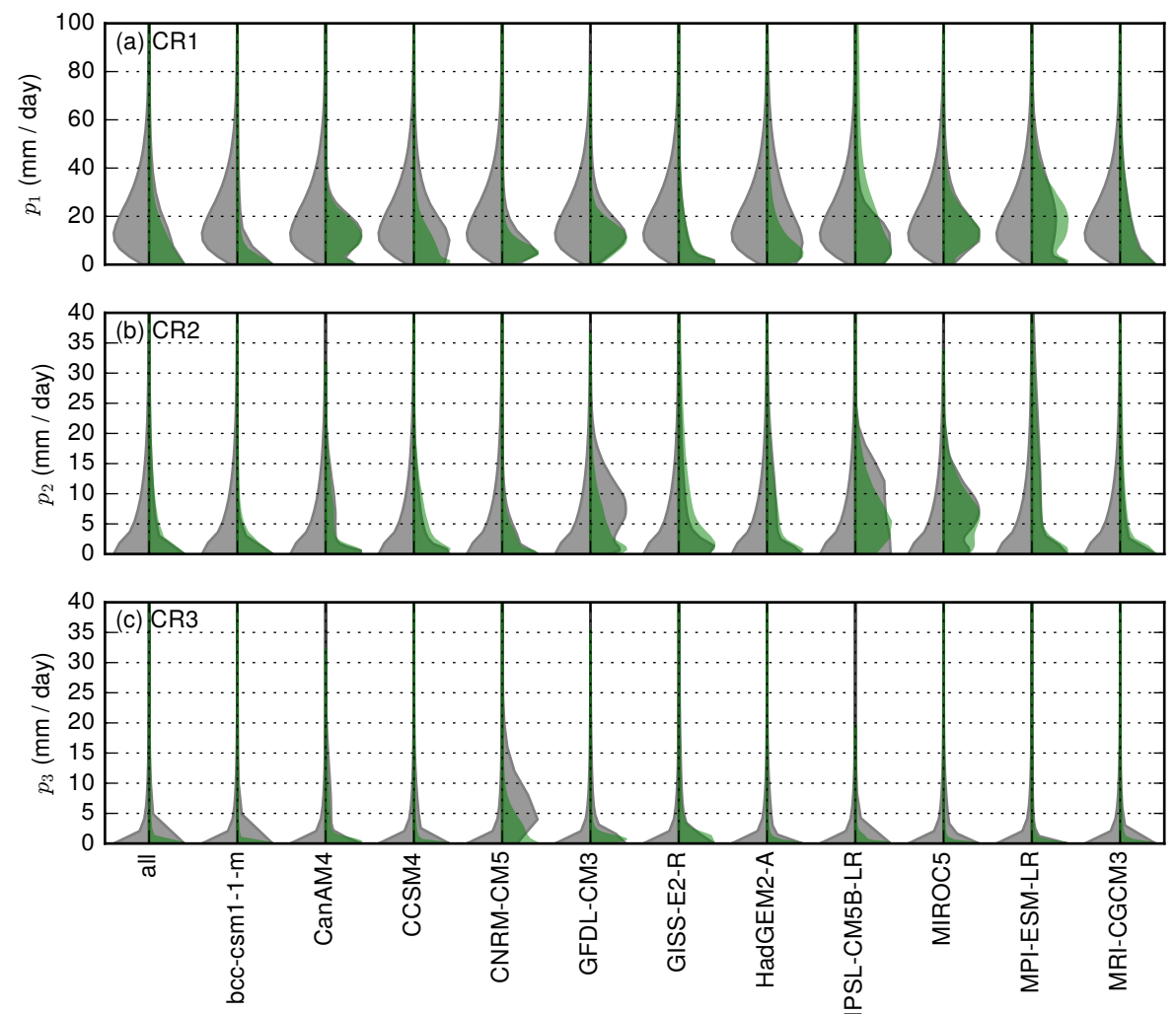

Fig. 8 The distributions in Fig. 6 for observations and the models (gray), overlaid with distributions from the $10 \%$ subset of samples with lowest Euclidean distances on the right-half (green).

underestimation of CR1 rain rates, as well as positive and negative biases for CR2 and CR3 amongst different models with a multimodel mean of near-zero. However, as opposed to the "pure" error in rain rates, the contribution to total rainfall error is modulated by the frequency of the cloud regime. This is illustrated in the case of MIROC5, in which the errors in the median rain rates for CR 1 and CR2 are of comparable magnitudes ( $\sim 5 \mathrm{~mm} /$ day; Fig. 6$)$, but because CR1 has a higher frequency in MIROC5 than CR2, its contribution to the total error is larger. This demonstrates the point that such error decomposition provides a more comprehensive perspective of the overall rainfall error than just the rain rate distributions.

The contribution from errors in the frequencies of the cloud regimes $(\Delta f \times p)$ is therefore strongly influenced by how well the model is able to simulate the occurrence of the regimes. Indeed, there is a close correspondence between Fig. 9 and Table 1. In particular, CanAM4, CCSM4, GFDL-CM3, HadGEM2-A and MRICGCM3 all overestimate the frequency of CR1 by a fairly large amount, resulting in a large positive contribution to the total rainfall error. However, in the case of CanAM4, CCSM4 and GFDL-CM3, this positive contribution is balanced by 


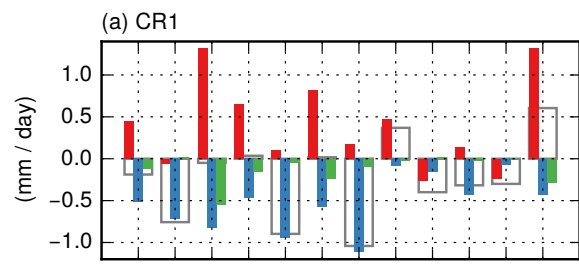

(b) CR2
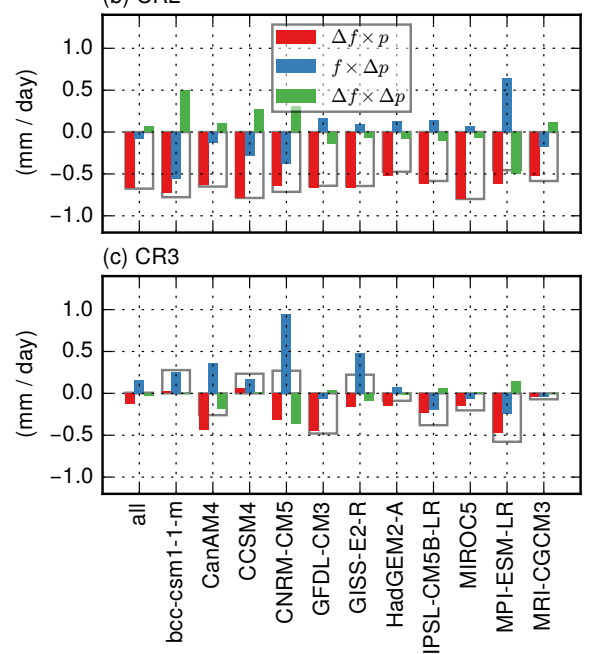

Fig. 9 Decomposition of the total rainfall error into the contribution from the error in CR frequency $(\Delta f \times p)$, the contribution from the error in rain rates $(f \times \Delta p)$, and the cross-term $(\Delta f \times \Delta p)$. The sum of all three errors for each model cloud regime is indicated by the gray box.

the negative error from the rain rates. In other words, these three models produce CR1 too frequently but with too low a rain rate, such that the contribution of error from CR1 is small. As for CR2 and CR3, consistent with the underestimation of their frequencies in nearly all models, the contributions are nearly all negative. The magnitudes of the errors are especially high for CR2, as models appear unable to produce these cirrus-dominated regime with sufficient frequency.

Lastly, the cross-terms $(\Delta f \times \Delta p)$ are, with a few exceptions, of lower magnitudes than the other two terms within the same model and CR. This demonstrates that the contribution from the second-order co-variation of the errors in frequency and rainfall is generally low, though it cannot be ignored in certain cases such as CR1 in CanAM4 and CR3 in CNRM-CM5.

\subsection{Geographical distribution of CR1 errors}

The error decomposition of the previous section provides a tropics-averaged analysis of the contributions from various aspects of the cloud regimes; further insights can be gleaned by examining the geographical distributions of these contributions. Here, we focus on CR1 due to its strong but diverse impact on tropical rainfall. 
Since the contribution from errors in frequency has similar geographical distribution to that of the anomalies in regime frequencies themselves, we can use Fig. 4 as an indication of this contribution. The five models (CanAM4, CCSM4, GFDLCM3, HadGEM2-A and MRI-CGCM3) identified in the previous section with a strong positive contribution from CR1 show overestimation of its occurrence in most areas in the tropics. More intriguingly, for other models, while the magnitudes of errors from CR1 frequency are low, there are considerable geographical variations in the errors. In fact, the low error in CR1 frequency in the tropics for these models (and the corresponding low contribution to total rainfall error) is not so much because the models are able to simulate CR1 accurately in all regions, but because there are compensating errors between different regions. Averaging the contributions from CR1 frequency over the tropics masks the biases in different geographical regions.

As for the geographical distributions of the error contributions from the rain rates of CR1, Fig. 10 shows a similar conclusion: a low tropics-averaged error is due to cancellations from different regions. Models with smaller rain rates errors from CR1 in Fig. 9 (HadGEM2-A, IPSL-CM5B-LR, MIROC5 and MPI-ESM-LR) also have substantial area in the tropics with a positive contribution. However, the regional biases are different across models. For example, an overestimation in the eastern Pacific is only present in HadGEM2-A, whereas an overestimation over eastern Indian Ocean is only clear in IPSL-CM5B-LR. In contrast, models such as CNRM-CM5 and GISS-E2-R, which have a large negative tropics-averaged error, show underestimation of CR1 rain rates in almost all regions of the tropics.

\section{Discussion}

4.1 Connection between clouds and precipitation in models

In Sec. 3.1, we showed that models have varying degrees of success in simulating the rain rates of the three convective cloud regimes. Due to the "fuzzy" nature of the regime assignment process in models, it was possible that some model regimes may include joint-histograms that do not possess the actual physical characteristics of their regime membership. Indeed, the mean joint-histograms of the model regimes (Fig. 3), while displaying broadly similar patterns to observed regime centroids, exhibited some deviations upon closer examination (e.g. greater proportion of clouds in the top-left thin cirrus bin for CR1). However, when restricting the evaluation to the subset of joint-histograms that bear the closest resemblance to observed centroids, there is no discernible or consistent improvement in the rain rates, leading us to conclude that an improved representation of clouds may not yield better rain rate distributions.

Looking at the difference in the mean joint-histograms between the subset (Fig. 7) and entire set (Fig. 3), and comparing it to the observed centroids (Fig. 1 ), it is clear, as expected, that restricting the model joint-histograms to the best matches shifts the cloud pattern towards the observed. For example, in CR1 of IPSL-CM5B-LR, there is an appreciable reduction in the overabundance of thin cirrus clouds (top-left bin); in CR1 of CNRM-CM5, the entire cloud distribution is shifted from overly-thick clouds towards optically-thinner clouds. Yet, the former example has improved, higher rain rates while the latter example has worse, lower 

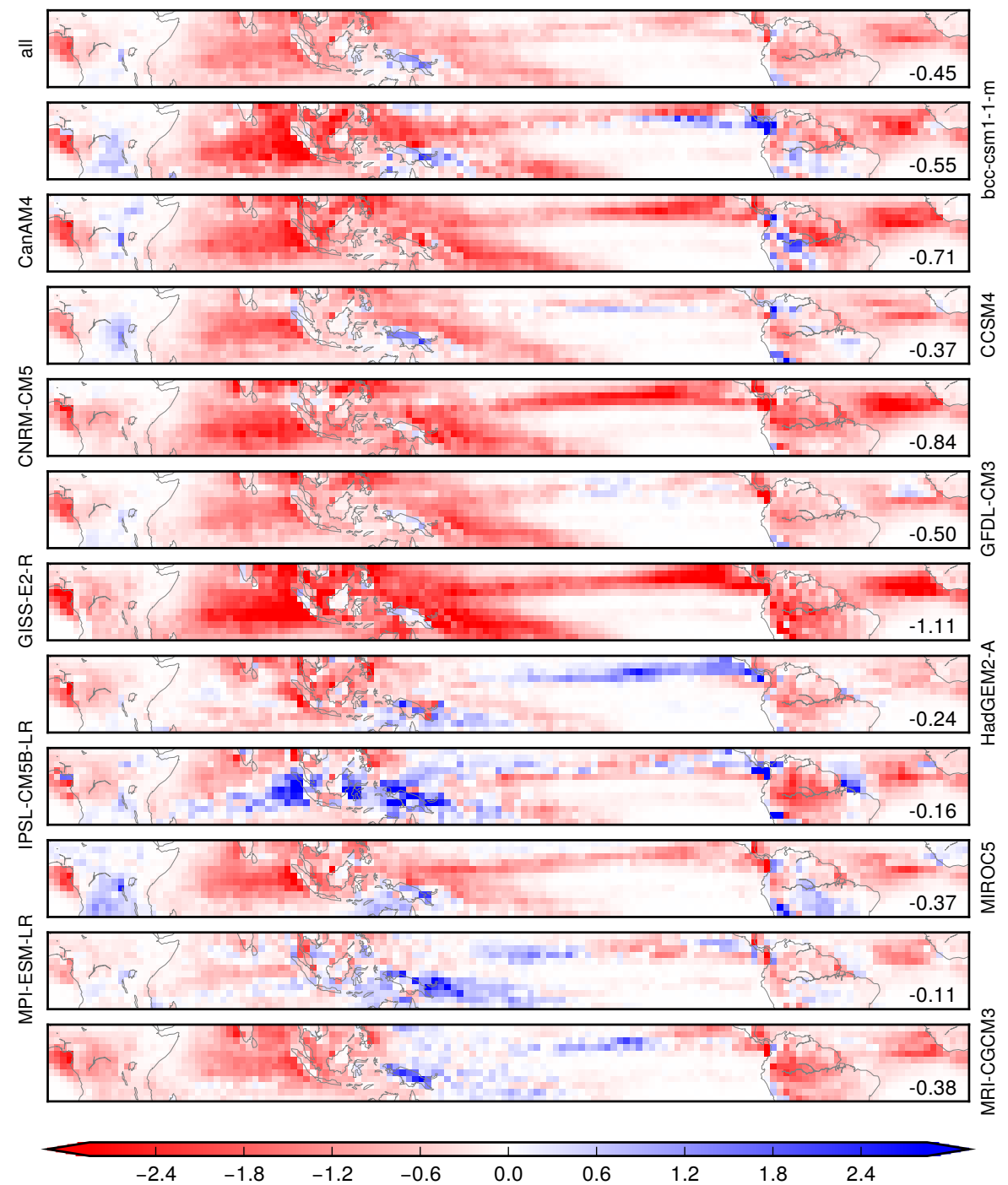

Fig. 10 Geographical distribution of the contributions from the error in mean rain rate $(f \times$ $\Delta p$ ) of CR1 for each model. The average tropical error for each model is shown in the number at the bottom-right. Note that we chose blue to indicate positive anomaly due to its association with wet conditions.

rain rates. In fact, a consistent result that emerges from this subset analysis is a relationship between the rain rate and the height or thickness of the cloud. If a joint-histogram has higher or thicker clouds, it will have stronger rain rates regardless of the absolute rainfall associated with clouds of a particular height and thickness. Therefore, any improvements to the cloud-precipitation relationship in the models will need to address the incorrect rain rates associated with each CTP- $\tau$ bin. 
4.2 Compensating errors between cloud regimes and regions

While the rain rate distributions of various cloud regimes are illuminating in terms of understanding how well models are able to produce the rainfall associated with each weather system, they do not provide the complete picture. As we have shown in Sec. 3.2, how often the regimes occur is also a relevant factor in determining the total rainfall in the tropics, which is perhaps of greater concern for issues such the total water budget in the tropics. Indeed, Fig. 9 illustrates this point well: although all models underestimate the rain rates of the intense CR1 (and thus suffer a negative error to total rainfall), this is partially offset by a positive frequency error in several models. In fact, the error due to underestimating the occurrence of CR2 has a greater impact on total rainfall in numerous models (Fig. 9 ). It is worth noting that the use of the reduced 3-dimensional vector that is common in model evaluation of cloud regimes (e.g. Gordon et al 2005; Williams and Webb 2009; Tsushima et al 2013; Jin et al 2017b) does improve the frequency of CR2 in the models, though at the expense of an overestimation in CR1 frequency. Therefore, both the regime frequency and the regime rain rate must be considered for a complete picture of total error in tropical rainfall.

On top of compensating errors between various regimes as well as between regime frequency and rain rate, Sec. 3.3 also identified errors in "well-performing" models over different regions in the tropics that cancel out upon spatial averaging. As a matter of fact, Figs. 4 and 10 suggest that a low error does not necessarily indicate that a model is good at producing the correct regime frequency and rain rate, but is often the result of an almost even presence of positive and negative biases. The presence of compensating errors may not be surprising, given that spatially- and temporally-averaged quantities, such as monthly zonal mean precipitation, are probably the main guidance during model development and thus likelier to better resemble observations. Hence, analyses involving error decomposition and regional breakdown can unmask compensating errors and provide a more comprehensive view of the weaknesses in rainfall simulations.

\section{Conclusions}

In this study, we investigated the tropical rainfall in 11 CMIP5 models through the lens of cloud regimes. In observations, cloud regimes are categorizations of various convective environments based on passive satellite retrievals of cloud properties. With the implementation of satellite simulators, we can identify model cloud regimes by assigning model clouds to observed regime centroids. We examined the rain rate distributions of the three convectively-active cloud regimes in the models. We find that many models underestimate the rain rates of CR1, which in observations represent organized convection, though a few models were broadly able to reproduce the observed rain rate distribution. For CR2 and CR3 which represents less organized convective environments, the models have varying performances with both positive and negative biases such that the ensemble of model values appear close to observations. Restricting to cases in which model clouds best resemble observed clouds does not necessarily improve the performance, which we argue is due to an incorrect rain rate associated with the cloud pixel of each CTP- $\tau$ combination. To attain a more comprehensive view of these errors on total tropi- 
cal rainfall, we performed an error decomposition that reflects the contribution of regime frequency and regime rain rates to total rainfall errors. Models generally have a negative contribution from CR1 rain rates and CR2 frequency, though in some cases, particularly for CR1, there are cancellations in the errors between frequency and rain rates. Furthermore, an examination of the geographical distributions of the errors revealed that a low tropics-averaged error are primarily a result of cancellation between positive and negative errors in different regions.

ISCCP cloud regimes have been regularly employed for the model evaluation of clouds and radiation (e.g. Williams et al 2005; Williams and Webb 2009; BodasSalcedo et al 2014; Mason et al 2015; Tsushima et al 2016; Jin et al 2017a), but this is the first time, to our knowledge, that they have been used to study model performance on rainfall. By examining model rainfall through cloud regimes, we place a stringent demand on models, as a good performance requires the model to represent both clouds and rainfall accurately at the same time. Such an approach transcends evaluations based on spatially- and temporally-averaged quantities, which are the primary guidance during model development. The benefit is a more informative categorization of the errors than a simple, straightforward evaluation of model rain rates, revealing weather systems that suffer deficiencies in models and existence of compensating errors.

Precipitation has perennially been a challenge in models. In our study, biases such as the underestimation of heavy rain (e.g. Stephens et al 2010) manifest in the rain rate distributions of CR1. The fact that rain rates do not improve when examined for only the best-matching clouds suggest a possible disconnect between the resolved variables, which determines the subgrid column profiles that the satellite simulator relies on, and the surface rainfall in the models, which is jointly a result from large-scale and convective (parametrized) precipitation. In particular, the lack of a representation for organized convection is an issue widely known to the convection community and model developers (e.g. Arakawa 2004; Moncrieff et al 2012; Rossow et al 2013; Houze et al 2015). While there is evidence that explicit representations of convection, such as through superparametrization or convective-permitting simulations, improve the distribution of rainfall (e.g. Meredith et al 2015; Kooperman et al 2016; Kendon et al 2017), the majority of models currently in use, including all in the CMIP5 repository, still employ conventional convective parametrizations. Since convection-resolving global climate models are still too computationally demanding in the near future, improved representation of tropical rainfall will have to come from the development of a better convective parametrization scheme.

Acknowledgements We are grateful for valuable feedback from Dongmin Lee. JT is supported by an appointment to the NASA Postdoctoral Program at Goddard Space Flight Center, administered by USRA through a contract with NASA (NNH15CO48B). LO and DJ gratefully acknowledge support by NASA's Modeling Analysis and Prediction program. CJ is supported by the ARC Centre of Excellence for Climate System Science (CE110001028). ISCCP data is available at https://isccp.giss.nasa.gov/. TMPA was provided by the NASA GSFC PPS team and NASA GES DISC, and can be downloaded at http://pmm.nasa.gov/data-access. The CMIP5 data was provided by the WCRP and archived by the PCMDI at http://pcmdi.llnl.gov/. 


\section{References}

Arakawa A (2004) The cumulus parameterization problem: Past, present, and future. J Clim 17(13):2493-2525, DOI 10.1175/1520-0442(2004)017<2493:RATCPP $>2.0$.CO;2

Bodas-Salcedo A, Webb MJ, Bony S, Chepfer H, Dufresne JL, Klein SA, Zhang Y, Marchand R, Haynes JM, Pincus R, John VO (2011) COSP: Satellite simulation software for model assessment. Bull Am Meteorol Soc 92(8):1023-1043, DOI 10.1175/2011BAMS2856.1

Bodas-Salcedo A, Williams KD, Field PR, Lock AP (2012) The Surface Downwelling Solar Radiation Surplus over the Southern Ocean in the Met Office Model: The Role of Midlatitude Cyclone Clouds. J Clim 25(21):7467-7486, DOI 10.1175/JCLI-D-11-00702.1

Bodas-Salcedo A, Williams KD, Ringer MA, Beau I, Cole JNS, Dufresne JL, Koshiro T, Stevens B, Wang Z, Yokohata T (2014) Origins of the Solar Radiation Biases over the Southern Ocean in CFMIP2 Models. J Clim 27(1):41-56, DOI 10.1175/JCLI-D-13-00169.1

Bony S, Webb M, Bretherton CS, Klein SA, Siebesma P, Tselioudis G, Zhang M (2011) CFMIP: Towards a better evaluation and understanding of clouds and cloud feedbacks in CMIP5 models. Clivar Exch 56(2):20-22

Chen Y, Del Genio AD (2009) Evaluation of tropical cloud regimes in observations and a general circulation model. Clim Dyn 32(2):355-369, DOI 10.1007/s00382-008-0386-6

Dai A (2006) Precipitation characteristics in eighteen coupled climate models. J Clim 19(18):4605-4630, DOI 10.1175/JCLI3884.1

Folkins I, Mitovski T, Pierce JR (2014) A simple way to improve the diurnal cycle in convective rainfall over land in climate models. J Geophys Res Atmospheres 119(5):2113-2130, DOI 10.1002/2013JD020149

Gordon ND, Norris JR, Weaver CP, Klein SA (2005) Cluster analysis of cloud regimes and characteristic dynamics of midlatitude synoptic systems in observations and a model. J Geophys Res 110(D15):D15S17, DOI 10.1029/2004JD005027

Handlos ZJ, Back LE (2014) Estimating Vertical Motion Profile Shape within Tropical Weather States over the Oceans. J Clim 27(20):7667-7686, DOI 10.1175/JCLI-D-13-00602.1

Hintze JL, Nelson RD (1998) Violin Plots: A Box Plot-Density Trace Synergism. Am Stat 52(2):181-184, DOI 10.1080/00031305.1998.10480559

Houze RA, Rasmussen KL, Zuluaga MD, Brodzik SR (2015) The variable nature of convection in the tropics and subtropics: A legacy of 16 years of the Tropical Rainfall Measuring Mission satellite. Rev Geophys 53:994-1021, DOI 10.1002/2015RG000488

Huffman GJ, Bolvin DT, Nelkin EJ, Wolff DB, Adler RF, Gu G, Hong Y, Bowman KP, Stocker EF (2007) The TRMM Multisatellite Precipitation Analysis (TMPA): Quasi-Global, Multiyear, Combined-Sensor Precipitation Estimates at Fine Scales. J Hydrometeorol 8(1):3855, DOI 10.1175/JHM560.1

Jakob C, Schumacher C (2008) Precipitation and Latent Heating Characteristics of the Major Tropical Western Pacific Cloud Regimes. J Clim 21(17):4348-4364, DOI 10.1175/2008JCLI2122.1

Jakob C, Tselioudis G (2003) Objective identification of cloud regimes in the Tropical Western Pacific. Geophys Res Lett 30(21):2082, DOI 10.1029/2003GL018367

Jiang X, Waliser DE, Xavier PK, Petch J, Klingaman NP, Woolnough SJ, Guan B, Bellon G, Crueger T, DeMott C, Hannay C, Lin H, Hu W, Kim D, Lappen CL, Lu MM, Ma HY, Miyakawa T, Ridout JA, Schubert SD, Scinocca J, Seo KH, Shindo E, Song X, Stan C, Tseng WL, Wang W, Wu T, Wu X, Wyser K, Zhang GJ, Zhu H (2015) Vertical structure and physical processes of the Madden-Julian oscillation: Exploring key model physics in climate simulations. J Geophys Res Atmospheres 120(10):4718-4748, DOI 10.1002/2014JD022375

Jin D, Oreopoulos L, Lee D (2017a) Regime-based evaluation of cloudiness in CMIP5 models. Clim Dyn 48(1-2):89-112, DOI 10.1007/s00382-016-3064-0

Jin D, Oreopoulos L, Lee D (2017b) Simplified ISCCP cloud regimes for evaluating cloudiness in CMIP5 models. Clim Dyn 48(1-2):113-130, DOI 10.1007/s00382-016-3107-6

Kang IS, Yang YM, Tao WK (2015) GCMs with implicit and explicit representation of cloud microphysics for simulation of extreme precipitation frequency. Clim Dyn 45(1-2):325-335, DOI $10.1007 / \mathrm{s} 00382-014-2376-1$

Kendon EJ, Ban N, Roberts NM, Fowler HJ, Roberts MJ, Chan SC, Evans JP, Fosser G, Wilkinson JM (2017) Do Convection-Permitting Regional Climate Models Improve Projections of Future Precipitation Change? Bull Am Meteorol Soc 98(1):79-93, DOI 10.1175/BAMS-D-15-0004.1 
Klein SA, Jakob C (1999) Validation and sensitivities of frontal clouds simulated by the ECMWF model. Mon Weather Rev 127(10):2514-2531, DOI 10.1175/15200493(1999) $127<2514$ :VASOFC $>2.0 . \mathrm{CO} ; 2$

Kooperman GJ, Pritchard MS, Burt MA, Branson MD, Randall DA (2016) Robust effects of cloud superparameterization on simulated daily rainfall intensity statistics across multiple versions of the Community Earth System Model. J Adv Model Earth Syst 8(1):140-165, DOI 10.1002/2015MS000574

Lee D, Oreopoulos L, Huffman GJ, Rossow WB, Kang IS (2013) The Precipitation Characteristics of ISCCP Tropical Weather States. J Clim 26(3):772-788, DOI 10.1175/JCLI-D11-00718.1

Lin JL, Kiladis GN, Mapes BE, Weickmann KM, Sperber KR, Lin W, Wheeler MC, Schubert SD, Del Genio A, Donner LJ, Emori S, Gueremy JF, Hourdin F, Rasch PJ, Roeckner E, Scinocca JF (2006) Tropical intraseasonal variability in 14 IPCC AR4 climate models. Part I: Convective signals. J Clim 19(12):2665-2690, DOI 10.1175/JCLI3735.1

Mason S, Fletcher JK, Haynes JM, Franklin C, Protat A, Jakob C (2015) A Hybrid Cloud Regime Methodology Used to Evaluate Southern Ocean Cloud and Shortwave Radiation Errors in ACCESS. J Clim 28(15):6001-6018, DOI 10.1175/JCLI-D-14-00846.1

Mekonnen A, Rossow WB (2011) The Interaction Between Deep Convection and Easterly Waves over Tropical North Africa: A Weather State Perspective. J Clim 24(16):4276-4294, DOI 10.1175/2011JCLI3900.1

Meredith EP, Maraun D, Semenov VA, Park W (2015) Evidence for added value of convectionpermitting models for studying changes in extreme precipitation. J Geophys Res Atmospheres 120(24):12,500-12,513, DOI 10.1002/2015JD024238

Moncrieff MW, Waliser DE, Miller MJ, Shapiro MA, Asrar GR, Caughey J (2012) Multiscale Convective Organization and the YOTC Virtual Global Field Campaign. Bull Am Meteorol Soc 93(8):1171-1187, DOI 10.1175/BAMS-D-11-00233.1

Oreopoulos L, Rossow WB (2011) The cloud radiative effects of International Satellite Cloud Climatology Project weather states. J Geophys Res 116(D12):D12,202, DOI 10.1029/2010JD015472

Rossow WB, Schiffer RA (1999) Advances in Understanding Clouds from ISCCP. Bull Am Meteorol Soc 80(11):2261-2287, DOI 10.1175/1520-0477(1999)080<2261:AIUCFI >2.0.CO;2

Rossow WB, Tselioudis G, Polak A, Jakob C (2005) Tropical climate described as a distribution of weather states indicated by distinct mesoscale cloud property mixtures. Geophys Res Lett 32(21):L21,812, DOI 10.1029/2005GL024584

Rossow WB, Mekonnen A, Pearl C, Goncalves W (2013) Tropical Precipitation Extremes. J Clim 26(4):1457-1466, DOI 10.1175/JCLI-D-11-00725.1

Stachnik JP, Schumacher C, Ciesielski PE (2013) Total Heating Characteristics of the ISCCP Tropical and Subtropical Cloud Regimes. J Clim 26(18):7097-7116, DOI 10.1175/JCLID-12-00673.1

Stephens GL, L'Ecuyer T, Forbes R, Gettlemen A, Golaz JC, Bodas-Salcedo A, Suzuki K, Gabriel P, Haynes J (2010) Dreary state of precipitation in global models. J Geophys Res 115(D24):D24,211, DOI 10.1029/2010JD014532

Sun Y, Solomon S, Dai A, Portmann RW (2006) How often does it rain? J Clim 19(6):916-934, DOI 10.1175/JCLI3672.1

Tan J, Jakob C, Lane TP (2013) On the Identification of the Large-Scale Properties of Tropical Convection Using Cloud Regimes. J Clim 26(17):6618-6632, DOI 10.1175/JCLI-D-1200624.1

Tan J, Jakob C, Rossow WB, Tselioudis G (2015) Increases in tropical rainfall driven by changes in frequency of organized deep convection. Nature 519(7544):451-454, DOI 10.1038 /nature14339

Taylor KE, Stouffer RJ, Meehl GA (2012) An Overview of CMIP5 and the Experiment Design. Bull Am Meteorol Soc 93(4):485-498, DOI 10.1175/BAMS-D-11-00094.1

Tromeur E, Rossow WB (2010) Interaction of Tropical Deep Convection with the Large-Scale Circulation in the MJO. J Clim 23(7):1837-1853, DOI 10.1175/2009JCLI3240.1

Tsushima Y, Ringer MA, Webb MJ, Williams KD (2013) Quantitative evaluation of the seasonal variations in climate model cloud regimes. Clim Dyn 41(9-10):2679-2696, DOI $10.1007 /$ s00382-012-1609-4

Tsushima Y, Ringer MA, Koshiro T, Kawai H, Roehrig R, Cole J, Watanabe M, Yokohata T, Bodas-Salcedo A, Williams KD, Webb MJ (2016) Robustness, uncertainties, and emergent constraints in the radiative responses of stratocumulus cloud regimes to future warming. 
Clim Dyn 46(9-10):3025-3039, DOI 10.1007/s00382-015-2750-7

Williams KD, Tselioudis G (2007) GCM intercomparison of global cloud regimes: Present-day evaluation and climate change response. Clim Dyn 29(2-3):231-250, DOI 10.1007/s00382007-0232-2

Williams KD, Webb MJ (2009) A quantitative performance assessment of cloud regimes in climate models. Clim Dyn 33(1):141-157, DOI 10.1007/s00382-008-0443-1

Williams KD, Senior CA, Slingo A, Mitchell JFB (2005) Towards evaluating cloud response to climate change using clustering technique identification of cloud regimes. Clim Dyn 24(7-8):701-719, DOI 10.1007/s00382-004-0512-z

Yuan W, Yu R, Zhang M, Lin W, Li J, Fu Y (2013) Diurnal Cycle of Summer Precipitation over Subtropical East Asia in CAM5. J Clim 26(10):3159-3172, DOI 10.1175/JCLI-D-1200119.1 
Climate Dynamics manuscript No.

(will be inserted by the editor)

\section{Supplementary Material for Evaluating Rainfall Errors in Global Climate Models through Cloud Regimes}

Jackson Tan • Lazaros Oreopoulos •

Christian Jakob

Received: date / Accepted: date

J. Tan

NASA Goddard Space Flight Center, Greenbelt, MD, USA and Universities Space Research Association, Columbia, MD, USA

E-mail: jackson.tan@nasa.gov

L. Oreopoulos

NASA Goddard Space Flight Center, Greenbelt, MD, USA

C. Jakob

ARC Centre of Excellence for Climate System Science and School of Earth, Atmosphere and Environment, Monash University, Clayton, Victoria, Australia 


\section{Contents of this file}

1. Figure $\mathrm{S} 1$

2. Table S1

\section{Introduction}

This supporting information provides one additional figure and one additional table in support of the original article. 


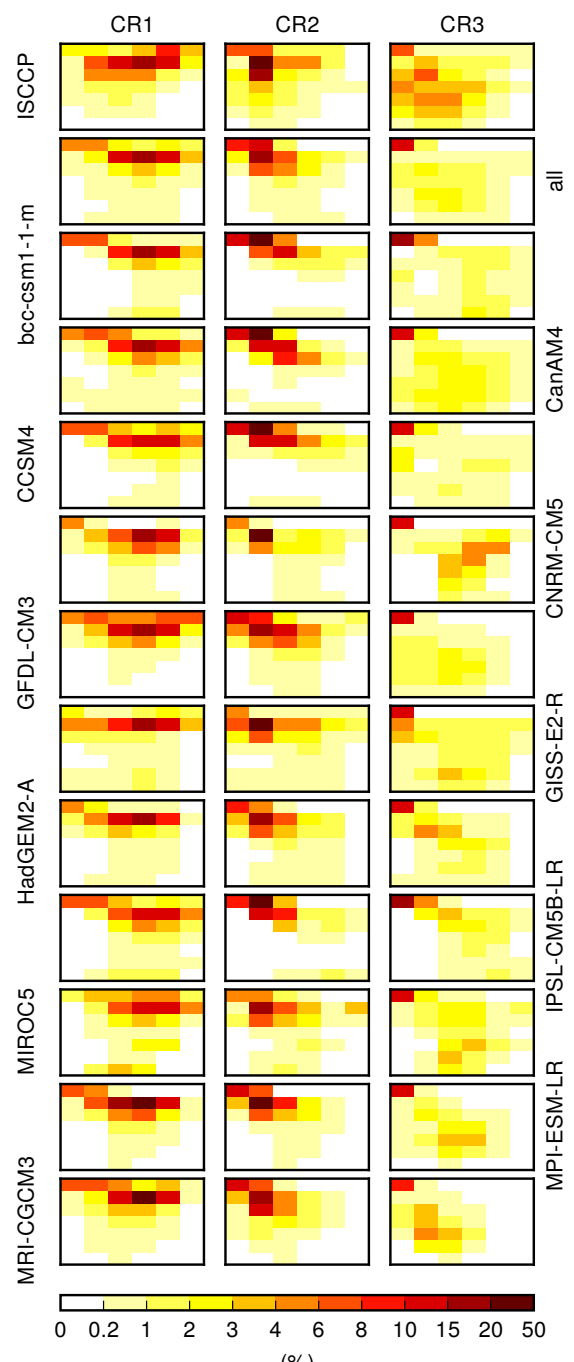

$(\%)$

Fig. S1 Mean joint-histograms of model CR1, CR2 and CR3, derived from the $10 \%$ of joint-histograms with the lowest Euclidean distance. The ISCCP mean joint-histograms are included for ease of comparison. 
Table S1 Frequencies of the six cloud regimes in observations (ISCCP) and in the models, based on the reduced 3-dimensional vector approach.

\begin{tabular}{|l|c|c|c|c|c|c|}
\hline Dataset & CR1 & CR2 & CR3 & CR4 & CR5 & CR6 \\
\hline \hline ISCCP & 0.081 & 0.067 & 0.223 & 0.100 & 0.426 & 0.103 \\
\hline bcc-csm1-1-m & 0.158 & 0.087 & 0.105 & 0.183 & 0.315 & 0.152 \\
\hline CanAM4 & 0.154 & 0.129 & 0.040 & 0.144 & 0.386 & 0.146 \\
\hline CCSM4 & 0.211 & 0.063 & 0.058 & 0.146 & 0.427 & 0.096 \\
\hline CNRM-CM5 & 0.202 & 0.123 & 0.108 & 0.146 & 0.350 & 0.072 \\
\hline GFDL-CM3 & 0.134 & 0.237 & 0.046 & 0.224 & 0.258 & 0.101 \\
\hline GISS-E2-R & 0.108 & 0.097 & 0.215 & 0.138 & 0.246 & 0.195 \\
\hline HadGEM2-A & 0.076 & 0.077 & 0.063 & 0.176 & 0.504 & 0.104 \\
\hline IPSL-CM5B-LR & 0.071 & 0.186 & 0.026 & 0.225 & 0.401 & 0.091 \\
\hline MIROC5 & 0.134 & 0.000 & 0.199 & 0.044 & 0.255 & 0.368 \\
\hline MPI-ESM-LR & 0.083 & 0.198 & 0.048 & 0.239 & 0.266 & 0.166 \\
\hline MRI-CGCM3 & 0.152 & 0.129 & 0.058 & 0.139 & 0.433 & 0.090 \\
\hline
\end{tabular}

